\title{
Postoperative analgesia after lumbar disc surgery: A comparison between ketorolac and opioid
}

\author{
Md. Mustafa Kamal ${ }^{1}$, Lt Col Abdullah Al Maruf ${ }^{2}$, Sabina Yeasmeen ${ }^{3}$, Abdul Hye ${ }^{4}$ \\ ${ }^{1}$ Department of Anaesthesia, Anaesthesia and Intensive Care Medicine, Bangabandhu Sheikh Mujib Medical University, Dhaka, \\ ${ }^{2}$ Department of Anaesthesia and Intensive Care, $\mathrm{CMH}$, Dhaka, ${ }^{3 \& 4}$ Bangabandhu Sheikh Mujib Medical University, Dhaka \\ Corresponding Author: E-mail: dr.mmkamal64@gmail.com
}

\begin{abstract}
Background Most spinal surgery is painful and good postoperative analgesia is important. Opioids are the traditional first-line treatment. Ketorolac has been used for postoperative pain relief. However, there is no data available about controlling postoperative pain with ketorolac after open lumbar discectomy or laminectomy in Bangladesah.

Objective To compare the efficacy of a Parentral ketorolac with conventional opioid for management of postoperative pain after lumbar disectomy or laminectomy.

Methods Sixty patients who underwent lumbar disectomy or laminectomy were randomly allocated into two groups. Group A $(n=30)$ patients received $30 \mathrm{mg}$ intramuscular ketorolac upon surgical closure and every 6 hours for 24 hours and intramuscular pethidine $1.5 \mathrm{mg} / \mathrm{kg} / \mathrm{b} . \mathrm{w}$. as needed (PRN). Group B $(n=$ 30) patients received only intramuscular pethidine $1.5 \mathrm{mgkg}-1 / \mathrm{b} . \mathrm{w}$. every 6 hours for 24 hours and as needed (PRN). Postoperative analgesia was assessed in both groups by Visual Analogue Scale at arrival in postoperative ward and at 6, 12 and 24 hours for 24 hours. Total postoperative narcotic consumption and side effects like post operative nausea and vomiting (PONV), dizziness, urinary retention and pruritus were also recorded.
\end{abstract}

Results Baseline data were comparable between the two groups. The mean VAS almost similar and less than 3 at different reading in both groups which indicate adequate postoperative analgesia and the differences were statistically not significant. The mean total cumulative amount of pethidine administered over $24 \mathrm{hrs}$ period was less in group A it was $64.31+19.13 \mathrm{mg}$ where as in group B was 161.23+21.25 mg. and the difference was statistically significant $(p<0.01)$. Incidences of side effects like PONV, urinary retention and pruritus were more in group $B$ than group $A$ and differences were statistically significant $(p<0.01)$.

Conclusion For postoperative pain management after lumbar spine surgery both ketorolac and traditional parental opioid found effective. Total opioid consumption is significantly less with ketorolac and side effects like PONV, dizziness, urinary retention and pruritus were more with opioid alone.

Keywords Ketorolac, opioid, postoperative pain, lumar spine surgery.

(JBSA 2010; 23(2): 56-61)

\section{Introduction}

Many patients with lumbar spine surgery experience moderate to severe pain in the recovery room or postoperative period. Although opioids are the traditional first-line treatment, ${ }^{1}$ the potential adverse effects often make physicians reluctant to increase the dosage to achieve adequate analgesia. ${ }^{2}$ Nonsteroidal anti inflammatory drugs (NSAIDs) provide effective analgesia for acute pain after minor and major surgery as a substitute for or as an adjunct to opioid analgesia and reduces opioid requirement during postoperative period..$^{3-11}$ 
The most recent parental non-steroidal antiinflammatory drug available for control of postoperative pain is ketorolac, a pyrolizine carboxylic acid derivative, structurally related to indomethacin. Ketorolac inhibit both cyclooxygenase and lipooxygenase enzyme thereby preventing synthesis of both prostaglandin and leukotrienes, and may release endogenous opioids. These properties of ketorolac make it more potent than other non-steroidal anti-inflammatory drugs and it is used in the treatment of post-operative pain of moderate or severe intensity ${ }^{12-16}$ The most common adverse effects reported with ketorolac include drowsiness, nausea, vomiting and dry mouth, but with no significant difference when compared to placebo. ${ }^{17}$ The analgesic potency of ketorolac 30mg has shown to be comparable with morphine $10-12 \mathrm{mg} \mathrm{I} / \mathrm{M} .{ }^{18}$

The postoperative pain requirements, however, depend on the type of procedure, size of skin incision and muscle dissection, and degree of bone involvement. Therefore, it is difficult to explorate the results of these investigations to other surgical procedures. Ketorolac has good analgesic potency and its opioid-sparing capacity. Because its onset of action is not immediate (about 30-60 minutes after IM injection), its use in severe acute pain in the postoperative period is best as an adjuvant to opioids, rather than as a sole agent for postoperative pain. This prospective randomized study was designed to assess the efficacy of a ketorolac with conventional opioid for the management of postoperative pain relief after lumbar disc surgery.

\section{Methods}

This randomized double blind prospective study was performed at BSMMU, Dhaka and Metropolitan Medical Centre, Dhaka in one calendar year from July 2009 to June 2010. After obtaining written informed consent from the patients, 60 ASA physical status I or II patients of either sex, aged 18-70 years scheduled for elective discectomy or decompressive laminectomy (1 or 2 levels) of the lumbar spine were included in the study. Patients with history of allergy, known or suspected to be drug abusers, renal diseases and history of peptic ulcer were excluded from the study. During the preoperative interview, patients were instructed how to assess postoperative pain by using the
Visual Analogue Scale (VAS) 0-10, $0=$ no pain, 10 $=$ the worst imaginable pain.

Operation was done under general anaesthesia with controlled ventilation. All patients received oral diazepam (5 mg) at night surgery. Pethidine $1 \mathrm{mgkg}-1$ and diazepam $0.1 \mathrm{mg} / \mathrm{kg}-1$ were slowly given intravenously before induction of general anesthesia. Induction was done with thiopentone 4-5 mgkg-1. After intubation with vecuronium $0.1 \mathrm{mgkg}-1$, anesthesia was maintained with $70 \%$ nitrous oxide in oxygen, halothane $0.5-1 \%$ and muscle relaxation was maintained with incremental doses of vecuronium. Patient's heart rate, blood pressure, respiratory rate and $\mathrm{SpO}_{2}$ were monitored in every 5 minutes interval. After completion of operation the patients were extubated by reversal of muscle relaxant and then admitted to the postoperative ward for 24 hours.

All eligible patients were randomized in to two groups. Group A $(\mathrm{n}=30)$ patients received $30 \mathrm{mg}$ I/M ketorolac upon surgical closure and every 6 hours for 24 hours and IM pethidine $1.5 \mathrm{mgkg}-1$ b.w. as needed $(\mathrm{PRN})$. Group B $(\mathrm{n}=30)$ patients received only I/M pethidine $1.5 \mathrm{mgkg}-1 \mathrm{~b} . \mathrm{w}$. every 6 hours for 24 hours and as needed (PRN).

Postoperative analgesia was assessed in both groups by Visual Analogue Scale (VAS). Observations were made in postoperative ward at arrival and at 6, 12 and 24 hours for 24 hours. Patient's heart rate, blood pressure, respiratory rate and $\mathrm{SpO}_{2}$ were observed accordingly. Total postoperative pethidine consumption and side effects like post operative nausea and vomiting (PONV), dizziness; urinary retention and pruritus were also recorded.

All results were expressed in mean $+\mathrm{SD}$ or percentage as applicable. Statistical analyses were carried out using Statistical Package for Social Science (SPSS) for Windows Version 17.0. Results were considered statistically significant if $\mathrm{P}$ value less than 0.05 .

\section{Results}

Patient's demographics and types of operation performed were similar and fairly comparable in both groups and differences were statistically not significant (Table I). Duration of surgical procedure and duration of anaesthetic procedure were similar 
in both groups and differences were statistically not significant (Table I). No patient was withdrawn from the study. Operating conditions were pronounced satisfactory by the surgeon concerned in all the cases.

Table I Demographic and operative patient data

\begin{tabular}{|c|c|c|c|}
\hline Characteristics & $\begin{array}{l}\text { Group A } \\
(\mathrm{n}=30)\end{array}$ & $\begin{array}{l}\text { Group B } \\
(\mathrm{n}=30)\end{array}$ & $\begin{array}{c}\mathrm{P} \\
\text { Value }\end{array}$ \\
\hline Age (Years) & $48.7+10.1$ & $49.1+10.3$ & $0.564^{\mathrm{NS}}$ \\
\hline Body weight (Kg) & $59.4+8.2$ & $60.2+7.9$ & $0.579 \mathrm{NS}$ \\
\hline Height (Cm) & $155.25+3.49$ & $153.65+4.04$ & $0.087 \mathrm{NS}$ \\
\hline \multicolumn{4}{|l|}{ Sex } \\
\hline Male & $20(66.66 \%)$ & $19(63.34 \%)$ & $0.768^{\mathrm{NS}}$ \\
\hline Female & $10(33.34 \%)$ & $11(36.66 \%)$ & $0.789 \mathrm{NS}$ \\
\hline \multicolumn{4}{|c|}{ ASA physical status } \\
\hline I & $17(56.66 \%)$ & $18(60 \%)$ & $0.776^{\mathrm{NS}}$ \\
\hline II & $13(43.44 \%)$ & $12(40 \%)$ & $0.784 \mathrm{NS}$ \\
\hline \multicolumn{4}{|l|}{ Types of operation } \\
\hline Discectomy & $16(53.33 \%)$ & $15(50 \%)$ & $0.812^{\mathrm{NS}}$ \\
\hline Laminectomy & $14(47.67 \%)$ & $15(50 \%)$ & $0.797 \mathrm{NS}$ \\
\hline $\begin{array}{l}\text { Duration of } \\
\text { Surgry(min) }\end{array}$ & $107.9+17.3$ & $108.2+16.7$ & $0.836^{\mathrm{NS}}$ \\
\hline $\begin{array}{l}\text { Duration of } \\
\text { Anaesthesia(min) }\end{array}$ & $119.6+22.8$ & $121.3+23.1$ & $0.821^{\mathrm{NS}}$ \\
\hline
\end{tabular}

Values are expressed in Mean $+\mathrm{SD}$ and $\mathrm{P}$ value $<0.05$ are significant

NS- Not significant

The pain intensity was measured by visual analogue scale in both groups. Statistical analysis revealed no significant difference in pain severity at arrival in postoperative ward and at 6, 12 and 24 hours (Table-II). The mean VAS almost similar and less than 3 at different reading in both groups which indicate adequate postoperative analgesia was maintained in both groups.

The mean total cumulative amount of pethidine administered over $24 \mathrm{hrs}$ period following the end of surgery was less in group A compared to group B. Mean dose of pethidine in group A was $64.31+19.13 \mathrm{mg}$ where as in group B was $161.23+21.25 \mathrm{mg}$. and the difference is statistically significant $\mathrm{P}<0.01$ (Table III). Incidence of postoperative side effects like PONV, dizziness, urinary retention and pruritus were recorded and shown in (Table-IV). ). Incidence of PONV, urinary retention and pruritus were more in group $B$ than group A and differences were statistically significant $(p<0.01)$. Dizziness was also more in group B than group A but difference was statistically not significant.

Table II Mean pain score (VAS) after surgery

\begin{tabular}{lccc}
\hline $\begin{array}{l}\text { Measurement } \\
\text { time }\end{array}$ & $\begin{array}{c}\text { Group A } \\
(\mathrm{n}=30)\end{array}$ & $\begin{array}{c}\text { Group B } \\
(\mathrm{n}=30)\end{array}$ & $\begin{array}{c}\mathrm{P} \\
\text { Value }\end{array}$ \\
\hline After surgery & $2.68+1.8$ & $2.71+1.7$ & $0.251 \mathrm{NS}$ \\
After 6 hours & $2.79+1.5$ & $2.89+1.6$ & $0.089 \mathrm{NS}$ \\
After 12 hours & $2.69+1.7$ & $2.76+1.6$ & $0.098 \mathrm{NS}$ \\
After 24 hours & $2.27+1.4$ & $2.31+1.5$ & $0.213 \mathrm{NS}$ \\
\hline
\end{tabular}

Values are expressed in Mean + SD. Test are done by unpaired student ' $\mathrm{t}$ ' test

NS- Not significant

Table III Mean total dose of pethidine administered over 24 hours period following surgery

\begin{tabular}{lccc}
\hline Variable & $\begin{array}{c}\text { Group A } \\
(\mathrm{n}=30)\end{array}$ & $\begin{array}{c}\text { Group B } \\
(\mathrm{n}=30)\end{array}$ & $\begin{array}{c}\mathrm{P} \\
\text { Value }\end{array}$ \\
\hline Mean dose of & $64.31+19.13$ & $161.23+21.25^{\mathrm{S}}$ & $\mathrm{P}<0.01$ \\
pethidine (mg) & & & \\
\hline
\end{tabular}

Test done by chi-square test, Values are expressed in Mean + SD, $\mathrm{P}<0.01-$ Statistically significant

Table IV Incidence of side effects during postoperative period

\begin{tabular}{lccr}
\hline Side effects & $\begin{array}{c}\text { Group A } \\
(\mathrm{n}=30)\end{array}$ & $\begin{array}{c}\text { Group B } \\
(\mathrm{n}=30)\end{array}$ & $\begin{array}{c}\mathrm{P} \\
\text { Value }\end{array}$ \\
\hline PONV & $1(3.33 \%)$ & $5(16.66 \%)$ & $\mathrm{P}<0.01^{\mathrm{S}}$ \\
Dizziness & $2(6.66 \%)$ & $4(13.33 \%)$ & $\mathrm{P}<0.061^{\mathrm{NS}}$ \\
Urinary retention & $1(3.33 \%)$ & $5(16.66 \%)$ & $\mathrm{P}<0.01^{\mathrm{S}}$ \\
Pruritus & $1(3.33 \%)$ & $4(13.33 \%)$ & $\mathrm{P}<0.01 \mathrm{~S}$ \\
\hline
\end{tabular}

Values are expressed in Percentage. Test are done by chi-square test

$\mathrm{P}<0.01$ - Statistically significant

NS- Not significant 


\section{Discussion}

Opioids remain the mainstay for postoperative analgesia, especially following major surgery. Pain, however, is a multi-factorial phenomenon that cannot be controlled adequately with simple monotherapy with opioids alone. ${ }^{19}$ Furthermore, opioid use is associated with dose-related adverse effects such as respiratory depression, nausea, vomiting, urinary retention, itching, and sedation. Opioids also reduce gastrointestinal (GI) motility, which may contribute to postoperative ileus. ${ }^{20,21}$ Their ability to control pain on movement also is limited, which may delay early mobilization and aggressive postoperative rehabilitation. ${ }^{22}$ To improve pain relief, and reduce the incidence and severity of adverse effects, a multi-modal approach to postoperative analgesia should be used. It is well known that spine surgery patients report highseverity postoperative pain. ${ }^{23,} 24$ Several studies have investigated risk factors for postoperative pain after spine surgery. These include psychologic, social profile, and preoperative pain severity. ${ }^{25-28}$ The use of minimally invasive neurosurgical techniques may decrease the occurrence of significant postoperative pain, ${ }^{29,30}$ but these techniques are not widely performed. The typical spine surgery patient has endured back pain chronically, with a good number of them on longterm pharmacologic analgesic therapy, sometimes requiring very large doses of analgesics and narcotics.

In this study we examined the effectiveness of a intramuscular ketorolac for treatment of postoperative pain after discectomy or decompressive laminectomy of the lumbar spine in the postoperative period. We also compare effectiveness with conventional intramuscular pethidine. The pain intensity was assessed using visual analogue scale (VAS). The mean VAS was less than 3 in both groups during different time periods during postoperative period, which indicate adequate postoperative analgesia was maintained in both group. Reports from several studies promote the use of NSAIDS in the perioperative period, but scarce information exists on their use for postoperative analgesia after spine surgery. Different routes of administration, different dosing regimens, and different drugs within this group have been studied. Le Roux et at reported that the use of NSAIDS as the sole medication for pain control after spine surgery was not sufficient to provide adequate analgesia, ${ }^{31}$ but when combined with opioids, the combination results in much better results than with either one alone. ${ }^{31-34}$ Reuben SS et al reported NSAIDS has opioid sparing effect for postoperative pain management after spine surgery. ${ }^{35}$

Ketorolac, given IM or IV, is the most investigated drug among the NSAIDS. It has good analgesic potency and its opioid-sparing capacity has been well documented. ${ }^{31-33}$ Turner DM et al reported ketorolac has provided good analgesia after lumbar spine surgery and less opioid requirement as well as it was cost effective. ${ }^{34}$ Because its onset of action is not immediate (about 30-60 minutes after IM injection), its use in severe acute pain in the postoperative period is best as an adjuvant to opioids, rather than as a sole agent. There is also a concern regarding the deleterious effects of NSAIDS on bone healing, because of the importance of PGE2 in the early stages of bone healing. ${ }^{36}$ High-dose $(120-240 \mathrm{mg} / \mathrm{d})$, but not lowdose, ketorolac has been associated with nonunion following spine fusion surgery. ${ }^{37} \mathrm{Low}$-dose ketorolac, in the absence of contraindications, may be a safe and effective adjuvant to an opioid-based regimen for acute postoperative pain management after spine surgery.

In this study cumulative narcotic doses were significantly lower with ketorolac $(\mathrm{P}<0.01)$. Reuben SS et el reported non-steroidal anti-inflammatory drugs have been found to enhance analgesia by reducing pain scores and reducing the amount of morphine used for analgesia. ${ }^{38}$ Sevarino FB et al has been shown that intramuscular ketorolac when combined with opioids, the combination results in much better results than with either one alone. 39 Various studies conclude that both ketorolac administered was effective in reducing morphine consumption as rescue analgesic postoperatively. ${ }^{40-42}$

Incidence of postoperative complications like PONV, dizziness, urinary retention and pruritus were observed in both groups. Incidences were more with pethidine then with ketorolac and differences were statistically significant $(\mathrm{P}<0.01)$ regarding PONV, urinary retention and pruritus. These side effects such as nausea, vomiting, urinary retention, itching were associated with dose-related opioid use. 
For management of postoperative pain following lumbar spine surgery ketorolac, when used with as needed narcotics (PRN) is effective like parental traditional opioid administration. The total opioid consumption is significantly less with ketorolac. Both the techniques were found effective and acceptable. But regarding side effects like PONV, dizziness, urinary retention and pruritus were more with opioid alone.

\section{References}

1. Schug SA, Merry AF, Acland RH. Treatment principles for the use of opioids in pain of nonmalignant origin. Drugs 1991; 42: 228-39

2. Nuutinen LS, Laitinen JO, Salomaki TE. A riskbenefit appraisal of injectable NSAIDs in the management of postoperative pain. Drug Saf 1993; 9: 380-93

3. Cashman J, McAnulty G. Nonsteroidal antiinflammatory drugs in perisurgical pain management. Mechanisms of action and rationale for optimum use. Drugs 1995; 49: 5170

4. Dahl JB, Kehlet H. Non-steroidal antiinflammatory drugs: rationale for use in severe postoperative pain. Br J Anaesth 1991; 66: 703-12

5. Perttunen K, Nilsson E, Kalso E. I.v. diclofenac and ketorolac for pain after thoracoscopic surgery. Br J Anaesth 1999; 82: 221-7

6. Elhakim M, Amine H, Kamel S, Saad F. Effects of intraperitoneal lidocaine combined with intravenous or intraperitoneal tenoxicam on pain relief and bowel recovery after laparoscopic cholecystectomy. Acta Anaesthesiol Scand 2000; 44: 929-33

7. Aubrun F, Langeron O, Heitz D, Coriat P, Riou B. Randomised placebo-controlled study of the postoperative analgesic effects of ketoprofen after spinal fusion surgery. Acta Anaesthesiol Scand 2000; 44: 934-9

8. Gupta A, Axelsson K, Allvin R, LiszkaHackzell J, Rawal N, Althoff B, Augustini BG. Postoperative pain following knee arthroscopy: the effects of intra-articular ketorolac and/or morphine. Reg Anesth Pain Med 1999; 24: $225-30$
9. Kostamovaara PA, Laitinen JO, Nuutinen LS, Koivuranta MK. Intravenous ketoprofen for pain relief after total hip or knee replacement. Acta Anaesthesiol Scand 1996; 40: 697-703

10. Collins SL, Moore RA, McQuay HJ, Wiffen PJ, Edwards JE. Single dose oral ibuprofen and diclofenac for postoperative pain. The Cochrane Library, Oxford, Issue 2, 2003

11. Staunstrup H, Ovesen J, Larsen UT, Elbaek K, Larsen U, Kroner K. Efficacy and tolerability of lornoxicam versus tramadol in postoperative pain. J Clin Pharmacol 1999; 39:834-41

12. Parke TJ, Millett S, Old S, Goodwin AP, Rice AS. Ketorolac for early postoperative analgesia. J Clin Anesth. 1995;7(6):465-9

13. DeAndrade JR, Maslanka M, Reines HD, Howe D, Rasmussen GL, Cardea J, et al. Ketorolac versus meperidine for pain relief after orthopaedic surgery. Clin Orthop Relat Res 1996;(325):301-12

14. White PF, Joshi GP, Carpenter RL, Fragen RJ. A comparison of oral ketorolac and hydrocodone-acetaminophen for analgesia after ambulatory surgery: arthroscopy versus laparoscopic tubal ligation. Anesth Analg. 1997;85(1):37-43

15. Smith LA, Carroll D, Edwards JE, Moore RA, McQuay HJ. Single-dose ketorolac and pethidine in acute postoperative pain: systematic review with meta-analysis. $\mathrm{Br} \mathrm{J}$ Anaesth 2000;84:48-58

16. Picard P, Bazin JE, Conio N, Ruiz F, Schoeffler P. Ketorolac potentiates morphine in postoperative patient-controlled analgesia. Pain 1997;73(3):401-6

17. Cepeda MS, Carr DB, Miranda N, Diaz A, Silva C, Morales O. Comparison of morphine, ketorolac, and their combination for postoperative pain: results from a large, randomized, double-blind trial. Anesthesiology 2005; 103(6): 1225-32

18. Gunter JB, Varugere AM, Harrington JF et al. Recovery and complication after tonsillectomy in children: A comparison of ketorolac and morphine. Anesth Analg 1995; 81: $1136-41$ 
19. Siddall PJ, Cousins MJ. Pain mechanisms and management: an update. Clin Exp Pharmacol Physiol 1995;22:679-88

20. Cali RL, Meade PG, Swanson MS, et al. Effect of morphine and incision length on bowel function after colectomy. Dis Colon Rectum 2000;43:163-8

21. Thorn SE, Wattwil M, Naslund I. Postoperative epidural morphine, but not epidural bupivacaine, delays gastric emptying on the first day after cholecystectomy. Reg Anesth 1992;17:91-4

22. Lynch EP, Lazor MA, Gellis JE, et al. Patient experience of pain after elective noncardiac surgery. Anesth Analg 1997;85:117-23

23. Bianconi M, Ferraro L, Ricci R, et al. The pharmacokinetics and efficacy of ropivacaine continuous wound installation after spine fusion surgery. Anesth Analg 2004;98:166-72

24. CohenBE, HartmanMB,Wade JT, et al. Postoperative pain control after lumbar spine fusion: patient-controlled analgesia versus continuous epidural analgesia. Spine 1997;22:1892-7

25. Klimek M, Ubben J, Ammann J. Pain in neurosurgically treated patients: a prospective observational study. J Neurosurg 2006;104:350-9

26. Kalkman CJ, Visser K, Moen J, et al. Preoperative prediction of severe postoperative pain. Pain 2003;105(3):415-23

27. Kotzer AM. Factors predicting postoperative pain in children and adolescents following spine fusion. Issues Compr Pediatr Nurs 2000;23:83-102

28. Epker J, Block AR. Pre-surgical psychological screening in back pain patients: a review. Clin J Pain 2001;17:200-5

29. Fessler RG. The development of minimally invasive spine surgery. Neurosurg Clin N Am 2006; $17: 401-9$

30. Oskouian RJ, Johnson JP. Endoscopic thoracic microdiscectomy. J Neurosurg Spine 2005; 3:459-64

31. Le Roux PD. Postoperative pain after lumbar disc surgery: a comparison between parenteral ketorolac and narcotics. Acta Neurochir (Wien) 1999;14:261-7

32. Gwirtz KH, Kim HC, Nagy DJ, et al. Intravenous ketorolac and subarachnoid opioid analgesia in the management of acute postoperative pain. Reg Anesth 1995;20(5):395401

33. Sevarino FB, Sinatra RS, Paige D, et al. The efficacy of intramuscular ketorolac in combination with intravenous PCA morphine for postoperative pain relief. J Clin Anesth 1992; 4(4):285-8

34. Turner DM,Warson JS, Wirt TC, et al. The use of ketorolac in lumbar spine surgery: a cost benefit analysis. J Spinal Disord 1995;8(3):206-12

35. Reuben SS, Connelly NR. Postoperative Analgesic Effects of Celecoxib or Rofecoxib After Spinal Surgery. Anesthesia and Analgesia 2000;91:1221-8

36. O'Keefe RJ, Tiyapatanaputi P, Xie C, et al. COX-2 has a critical role during incorporation of structural bone allografts. Ann N Y Acad Sci 2006;1068:532-42

37. Reuben SS. High dose nonsteroidal antiinflammatory drugs compromise spinal fusion. Can J Anaesth 2005;52(5):506-12

38. Reuben SS, Connelly NR, Steinberg R. Ketorolac as an adjunct to patient-controlled morphine in postoperative spine surgery patients. Reg Anesth 1997; 22: 343-6

39. Sevarino FB, Sinatra RS, Paige D. The efficacy of intramuscular ketorolac in combination with intravenous PCA morphine for postoperative pain relief. J Clin Anesth 1992; 4(4):285-8

40. Gillis JC, Brogden RN. Ketorolac: a reappraisal of its pharmacodynamic and pharmacokinetic properties and therapeutic use in pain management. Drugs 1997; 53: 139-88

41. Gerancher JCM, Ronald W, Joseph M. Transient paraperasis after postdural puncture spinal hematoma in patient receiving ketorolac. Anesthesiology 1997; 86: 490-4

42. Brain F, Edna Z, Eli G et al. Diclofenic does not decrease renal blood flow or glomerular filtration in elderly undergoing orthopedic surgery. Anesth Analg 1999; 88: 149-54 